\title{
Psychologists' Practices, Stressors, and Wellness in Academic Health Centers
}

\author{
Amy M. Williams ${ }^{1}$ (D) Bonney Reed ${ }^{2} \cdot$ Mariella M. Self ${ }^{3} \cdot$ William N. Robiner $^{4} \cdot$ Wendy L. Ward $^{5}$
}

Published online: 14 November 2019

(c) Springer Science+Business Media, LLC, part of Springer Nature 2019

\begin{abstract}
Burnout has been identified as widely prevalent in physicians and other health professions. However, relatively little has been written about burnout in psychologists. The current study reviews the literature investigating professional wellness, sources of stress, and burnout in practicing psychologists. Based on a survey of members of the Association for Psychologists in Academic Health Centers' $(n=93)$, stress levels, burnout, and work satisfaction in health service psychologists in academic health centers (AHCs) were examined. Respondents indicated some level of burnout ranging from having no symptoms (8\%) to being occasionally stressed (59\%), symptoms won't go away (12\%), definitely burning out (18\%), or being completely burned out (3\%). Most respondents described working at high levels, including "at full capacity" (41\%) or being "overextended" (39\%). Despite these concerns, most respondents indicated satisfaction with their positions (42\% "very satisfied," 44\% "somewhat satisfied") and recommended careers as psychologists in medical settings (50\% strongly; $34 \%$ moderately). Most commonly perceived sources of stress included clinical load, salary, insufficient protected time for research, teaching, education, and supervision, insufficient psychologists to meet the need, and non-billable clinical activities. Consistent with the physician literature, workload was associated with burnout and burnout was associated with decreased professional satisfaction. The current study narrows the gap in the literature on the stress psychologists experience in AHCs and explores findings within the broader literature about health professional burnout. Greater understanding is needed about factors that affect burnout in health service psychologists, identification and modification of risk factors, and prevention strategies.
\end{abstract}

Keywords Professional wellness $\cdot$ Burnout $\cdot$ Resilience $\cdot$ Psychologist $\cdot$ Academic health center

\section{Introduction}

Psychologists' clinical and other professional activities expose them to various stressors that challenge coping and influence their state of wellness (Berjot, Altintas, Grebot, \&

Amy M. Williams

awilli50@hfhs.org

Bonney Reed

bonney.reed-knight@emory.edu

Mariella M. Self

mmself@texaschildrens.org

William N. Robiner

robin005@umn.edu

Wendy L. Ward

wward@uams.edu

1 Department of Otolaryngology - Head \& Neck Surgery, Henry Ford Health System, 2799 W. Grand Blvd, Detroit, MI 48202, USA
Lesage, 2017). Psychologists' practices vary greatly; the settings in which they work and the populations they serve can affect stress levels and risk for burnout (Raquepaw \& Miller, 1989; Kullgren, Tsang, Ernst, \& Carter, 2015; Rupert, Miller, \& Dorociak, 2015). Evidence that burnout can be

2 School of Medicine, Emory University, 1400 Tullie Circle \#8332, Atlanta, GA 30329, USA

3 Psychiatry and Behavioral Sciences, College of Medicine, Texas Children's Hospital Psychology Service, Baylor University, 6701 Fannin St. Ste. 1600, Houston, TX 77030, USA

4 Division of General Internal Medicine, Department of Pediatrics, University of Minnesota, MMC 741, 420 Delaware St SE, Minneapolis, MN 55455, USA

5 Office of Interprofessional Education, College of Medicine, University of Arkansas for Medical Sciences, 1 Children's Way, Slot 512-21, Little Rock, AR 72202, USA 
related to work settings (Rupert \& Morgan, 2005) underscores the need to better understand sources of stress, rates of burnout, and ways to reduce risk in psychologists working in specific types of healthcare settings. Similarly, factors that influence professional wellness, which has been described as "the enduring quality in one's professional functioning over time and in the face of professional and personal stressors" (Coster \& Schwebel, 1997), should be investigated.

Academic health centers (AHCs) are unique practice settings, providing patients and communities with primary healthcare and/or specialized services (e.g., transplant) for complex diseases and extensive injuries that may not otherwise be available in the region and that often serve as safetynet facilities. AHCs have more complex missions than other health facilities. They also promote cutting-edge research and train the next generation of health professionals. A groundswell of research over the past 10 years has focused on professional wellness, stressors, and burnout in AHCs (e.g., Wright, Khetani, \& Stephens, 2011; Shanafelt, et al., 2015). This research has primarily focused on physicians (i.e., Wright et al., 2011; Shanafelt et al., 2015) and nurses (i.e., Hoff, Carabetta, \& Collinson, 2017). However, there has been relatively little examination of these phenomena in AHC psychologists (Kleespies et al., 2011). Existing literature on stress generally focuses on psychologists working in more traditional settings (schools, agencies, private practice, etc.) rather than diverse, interprofessional healthcare settings such as AHCs.

\section{Burnout and Stressors in AHCs}

Burnout is defined as a constellation of lowered physical energy (exhaustion), lowered emotional energy (depersonalization and cynicism), and lowered self-efficacy with a sense of disconnection from the perceived meaning and purpose of work (Maslach, Jackson, \& Leiter, 1997). It has long been recognized as an occupational hazard in professions that serve people, such as in healthcare and education (Maslach \& Leiter, 2016). Freudenberger (1974, $1990)$ coined the term "burnout" in human service workers to describe feelings of depersonalization, emotional exhaustion, and absence of feelings of self-accomplishment that may result from prolonged work in emotionally challenging situations, such as healthcare and psychological practice. Additionally, the World Health Organization included burnout in the 11th revision of the International Classification of Diseases (ICD-11) in the chapter: "Factors influencing health status or contact with health services" (WHO, 2019). While the ICD-11 does not consider burnout a medical condition, it is classified as an occupational phenomenon that encompasses feelings of energy depletion or exhaustion, mental distance from one's job or feelings of negativism/cynicism related to one's job, and reduced professional efficacy, that exist in the occupational context (i.e., not to be applied to other areas of life) (WHO, 2019).

Indeed, in recent years, concern about burnout among health professionals has rightfully increased: The National Academy of Sciences contends that it is an under-recognized threat to safe, high-quality care (Dyrbye et al., 2017). The Blue Ridge Academic Health Group report (2017-1018) considers challenges to health professionals' well-being an epidemic and makes the case that addressing health professionals' well-being is a moral imperative for AHCs. Bodenheimer and Sinsky (2014) recommended that improving the work life of health professionals be added as the fourth aim to the triple aims of health reform (i.e., improving patient care and the patient experience, population health, and reducing costs; Institute for Healthcare Improvement, 2010).

Common characteristics of, and processes within, healthcare settings affect health professionals' stress level. Some of these include: increasing productivity requirements and clinical workloads (van Olmen et al., 2011); long and burdensome work hours (Ozyurt, Hayran, \& Sur, 2006); responsibility for critical decisions and the lives of patients (Wright et al., 2011); rapid changes in healthcare delivery practices and reimbursement models (Tomcavage \& Garrett, 2009); and challenges associated with clinical documentation and electronic health records (EHRs; Robertson, Robinson, \& Reid, 2017). Interestingly, although EHRs are being widely adopted, a survey of 20,000 physicians indicated that $45.8 \%$ though it detracted from their efficiency and $47.1 \%$ thought it detracted from patient interactions, while only $32.1 \%$ thought it improved quality of care (The Physicians' Foundation, 2014), which raises questions about whether the benefits are worth the toll on clinicians who use it. Other stressors in AHCs include resource constraints and tight budgets (Saver, 2009); administrative demands (Van Dyke \& Seger, 2013); regulatory burdens, and limited research funds, including those necessary to track outcomes that are required for value-based/outcome-based reimbursement models (Moses \& Dorsey, 2012). Moreover, health professionals in AHCs often encounter additional stressors and competing demands as they seek to achieve professional and academic success (e.g., promotion and tenure) while fulfilling their institutions' triple mission of clinical service, education, and research. Unlike academicians in other settings, their appointments and schedules are generally year-round, without the cyclical breaks (e.g., seasonal academic breaks) that provide more structured and predictable opportunities for research, rejuvenation, and recreation. A recent estimate of burnout in medical schools was that $10 \%$ of faculty feel burned out and 19\% feel they are burning out, with an additional 43\% reporting feeling stressed (Dandar, Bunton, \& Grigsby, 2018). 
As the concerns about burnout and resilience have ascended in salience and priority in AHCs, there has been a significant increase in the measuring of, and intervening in, burnout and resilience in physicians (i.e., Shanafelt et al., 2015), undergraduate and graduate medical education (i.e., Shi, Gugio, Crowe, \& Way, 2018; Mendelsohn, Despot, Gooderham, Singhal, Redekop, \& Toyota, 2018), and nurses (i.e., Branch \& Klinkenberg, 2015). While psychologists are often involved in these intervention programs as consultants, educators, or coaches, the effects of burnout or interventions for promoting resilience are not often discussed as applied to psychologists as health professionals and involved in direct clinical care.

\section{Stress and Burnout in Health Professional Disciplines}

Stress and burnout affect health professionals across disciplines. The health professions share many common goals, opportunities, resources, and challenges, while also having some unique roles, tasks and trials. The National Academy of Medicine's conceptual model of factors affecting clinician well-being and resilience denotes the multifactorial realities contributing to clinicians' stress levels (see Brigham et al., 2018).

\section{Physicians}

Two themes identified in the culture of medicine that heighten risk for burnout are "patients come first" and "show no weakness." These have been engrained in medical education and often reinforced by attending physicians (Drummond, 2015). Across subspecialties and care settings more than half of US physicians (54\%) have been estimated to experience some degree of professional burnout (Shanafelt et al., 2015). Stress and burnout have negative impacts on physicians' and residents' physical health (Panagopoulou, Montogomery, \& Benos, 2006). Burnout in physicians is also associated with lower patient satisfaction, less optimal patient care quality, higher medical error rates and safety concerns, higher mortality ratios, higher physician turnover, and higher rates of physician substance abuse, (Arora, Asha, Chinnappa, \& Diwan, 2013; Firth-Cozens \& Greenhalf, 1997; Gardiner, Sexton, Durbridge, \& Garrard, 2005; Linzer, 2018; Shanafelt et al., 2015; Welp \& Manser, 2016; Williams \& Skinner, 2003). Higher burnout rates in physicians are also associated with increased incidence of mental health problems (20\%; Zwack \& Schweitzer, 2013). The estimated 400 physician suicides per year is a higher per capita rate than seen in the general public (Gold, Sen, \& Schwenck, 2013) or other stressful business occupations (Peterson et al., 2018). The formidable costs of physician burnout are estimated to total $\$ 150$ billion/year (Blue Ridge Academic Health Group, 2017-2018). To combat health professional burnout more swiftly and effectively, the National Academy of Medicine (NAM, 2017) in conjunction with the Association of American Medical Colleges (AAMC) and the accreditation Council for Graduate medical Education (ACGME) created the Action Collaborative on Clinician Well-Being and Resilience to enhance understanding and better coordinate efforts (Dzau, Kirch, \& Nasca, 2018).

\section{Other Health Professionals}

Of course, stress and burnout are not limited to physicians. The literature on stress in health professionals is burgeoning across professions, as it is increasingly perceived as an urgent, national concern (Dyrbye, Varkey, Boone, Satele, Sloan, \& Shanafelt, 2013; Shanafelt et al., 2015). Despite the heterogeneous stressors and protective factors across disciplines, various health professionals has been noted to experience high levels of stress and burnout (Shanafelt et al., 2015), including nurses (Branch \& Klinkenberg, 2015), dentists (American Dental Association, 2017), physician assistants (Benson et al., 2016), pharmacists (Mott, Doucette, Gaither, Pedersen, \& Schommer, 2004), audiologists (Severn, Searchfield, \& Huggard, 2012), respiratory therapists (Shelledy, Mikles, May, \& Youtsey, 1992), and others. Increased burnout in health professionals is a concern on both the individual level and institutional level-healthcare costs for taking care of providers is skyrocketing (Studer Group, 2012), with higher turnover (Studer Group, 2012), and increasing rates of health professionals leaving their professions prematurely (Pololi \& Knight, 2005).

\section{Psychologists}

Psychologists' emotionally evocative work in the context of stressful healthcare settings renders them at risk for distress and burnout (American Psychological Association Board of Professional Affairs Advisory Committee on Colleague Assistance, 2006). Baker (2003) described burnout in psychologists as the "terminal phase of therapist distress" (p. 21) i.e., at the severe end of a continuum of distress. The fatigue, emotional blunting, and disconnectedness that can be associated with burnout may impair psychologists' empathic ability to identify emotion or pain in others, the motivation to respond to these emotions appropriately, and the ability to hold the difficult emotions of another person (Figley, 2002). The potential consequences of psychologist burnout include impaired professional competence, interpersonal distress, and poor therapeutic outcomes (Morse, Salyers, Rollins, Monroe-DeVita, \& Pfahler, 2012), similar to the consequences seen in other health professionals 
around suboptimal patient care, increased medical error rates, higher mortality, and professional turnover.

Although little is known about how widespread distress, burnout, and mental health conditions are in psychologists (Kleespies et al., 2011), surveys of psychologists in general reveal concerning prevalence of burnout presumably related, in part, to the stressful nature of their work. Rupert and Morgan's (2005) survey of 571 APA members found psychologists had higher mean Emotional Exhaustion (EE) and Depersonalization (DP) scores than other mental health professionals, and low Personal Accomplishment (PA) scores on the Maslach Burnout Inventory (MBI) Human Services Survey (Maslach et al., 1997). Emotional exhaustion was related to long work hours, time consumed by administrative and paperwork tasks, low managed care reimbursement rates, and patient factors such as higher rates of negative patient behaviors (Rupert \& Morgan, 2005), again similar to those experienced by non-psychologist health professionals.

The 2009 APA Colleague Assistance and Wellness Survey of 658 psychologists identified multiple stress indicators with respondents reporting overly challenging work-life balance $(72 \%)$, burnout or compassion fatigue (59\%), experiencing significant stressors (51\%), at least some disruption in professional functioning due to anxiety, depression, or burnout (40-60\%), use of psychotropic medication (34\%), and suicidal ideation (18\%; Bridgeman \& Galper, 2010). Even though the CDC's methodology for tracking suicide rates by profession is not sufficiently granular to yield estimates for psychologists per se, suicidality is concerning in psychologists. In a sample of 800 psychologists, Pope and Tabachnick (1994) found a majority had been in psychotherapy, most of whom experienced depression; 29\% disclosed suicidal ideation and $4 \%$ reported a past suicide attempt.

Since the 1980s, the APA has acknowledged the existence of distress and impairment in the profession (Bridgeman \& Galper, 2010). In light of the broader emerging literature about burnout in health professionals in AHCs, it is important to ascertain how increasing stressors might be affecting the prevalence of distress and burnout in AHC health service psychologists. The limited literature addressing psychologist stress is based on large, diverse groups of psychologists. Dandar et al. (2018) estimated rates of burnout as $11 \%$ and of burning out as $20 \%$ in clinical Ph.D.s within medical school faculties. However, while many of the stressors contributing to burnout in physicians and other health professional are applicable to psychologists in AHCs, the impact of these stressors in this population remains unknown. To our knowledge, the literature has not addressed health service psychologists specifically in AHCs. To address this gap, the present study was designed to assess levels of burnout and sources of stress in AHC psychologists to increase understanding of workforce wellness and the multidimensional stressors health service psychologists encounter in these settings.

\section{Methods}

A link to an online membership survey was emailed to members of the Association of Psychologists in Academic Health Centers (APAHC; Section VIII of APA Division 12 [Clinical Psychology]), with one section of the survey addressing wellness and stress. APAHC (formerly the Association of Medical School Psychologists) formed in 1982 to address and represent the interests of psychologists working in medical schools spanning their clinical, research, education, and administrative, roles. APAHC serves a diverse community of AHC psychologists including clinical, counseling, health, and pediatric psychologists, neuropsychologists, students, and others.

The 65-item survey was designed jointly by the APAHC Membership and Research Committees. Historically, APAHC has conducted membership surveys periodically to delineate demographics of the membership and assess current issues and satisfaction with the organization. Items assessed (a) demographics (14 items); (b) satisfaction with existing membership services (14); (c) current trends in the field (3); (d) roles in education (13) and leadership (6); and (e) professional wellness and sources of stress (15). Free response options allowed comments within content areas. The survey was open for 8 weeks. The initial email invitation was sent to APAHC membership, followed by 2 reminder emails.

Four items assessed wellness: two addressing burnout and two assessed career satisfaction. A work capacity item was adapted from item 30 of the Survey of American Physicians 2014 (specifically included: "Which of the following best describes you?"; "I am overextended," "I am at full capacity," "I am near full capacity," "I have time to see more patients/assume more duties"; [The Physicians Foundation, 2014]). Another item, "How strongly would you recommend others to pursue a career as a psychologist in an academic health center, medical school, or teaching hospital? Strongly, moderately, mildly, unsure, against" was modified from item 11 of the Survey of American Physicians 2014 (The Physicians Foundation, 2014). A burnout item from earlier research was also included ("Based on your definition of burnout, how would you rate yourself? No symptoms, occasionally stressed, definitely burning out, symptoms of burnout won't go away, completely burned out"; Dolan et al., 2015). A job satisfaction item was adapted from the Quality of Worklife Questionnaire created by the Centers for Disease Control (CDC)'s National Institute for Occupational Safety and Health ("All-in-all satisfaction with current position? 
Very satisfied, somewhat satisfied, somewhat dissatisfied, very dissatisfied"; CDC, 2019).

Three follow-up requests for survey completion were emailed. No personal identifiers were collected to ensure that responses were anonymous. Institutional IRB review and exempt status were obtained from the University of Arkansas for Medical Sciences.

\section{Results}

The response rate was 59\% (93 of 158), which is considered an acceptable response rate for a survey of this nature (i.e., Shanafelt et al., 2012). In the resulting sample $(n=93)$, most respondents were female, White, non-Hispanic, and with $\mathrm{Ph} . \mathrm{D}$. degrees, which is generally consistent with APAHC membership demographics (see Table 1). Respondents were relatively distributed across the career span as reflected in years since doctoral degree and academic rank.

Respondents reported working more than a standard 40-hour work week at their workplaces $(M=47 \mathrm{~h}$; $\mathrm{SD}=7.98$; Median $=49.0$ ) and an additional $7.36 \mathrm{~h}$ on workrelated activities at home per week, for a total of greater than $54 \mathrm{~h}$ worked per week (see Table 2). Eighty percent of respondents reported feeling at full work capacity $(41 \%)$ or overextended $(39 \%)$, with only $3 \%$ reporting having time for more work.

A majority (59\%) of psychologists felt occasionally stressed. The mean level of reported burnout ranged between "occasionally stressed." Eighteen percent reported "definitely burning out." Fifteen percent reported persistent symptoms of burnout and 3\% reported feeling completely burned out. Only $8 \%$ denied having any symptoms of burnout.

Despite describing long work hours and sentiments that they were working toward the upper limit of their capacity, respondents generally reported satisfaction with their positions. Most felt somewhat (44\%) to very satisfied (42\%). Only $4 \%$ were very dissatisfied. Respondents were moderately (34\%) to strongly (50\%) inclined to encourage others to pursue careers as psychologists in AHCs, medical schools or teaching hospitals. Only $1 \%$ recommended against such careers.

Expectations for outpatient billing hours were reported to range from 0 to 40 , with a mean of $14.81 \mathrm{~h} /$ week $(\mathrm{SD}=11.82)$ and a median of $14.50 \mathrm{~h}$ per week, with low expectations for inpatient hours. When respondents with zero outpatient billing hours were excluded from analyses, the mean expectation was $18.74 \mathrm{~h} /$ week $(\mathrm{SD}=10.13)$, with a median number of 20.00 expected hours. Non-billable time associated with clinical work was about 7 additional hours/week, ranging as high as $20 \mathrm{~h} /$ week. Higher numbers
Table 1 Demographic characteristics of respondents $(n=93)$

\begin{tabular}{|c|c|c|}
\hline \multirow[t]{2}{*}{ Demographic } & \multicolumn{2}{|c|}{ Respondent sample } \\
\hline & $\%$ & $n$ \\
\hline \multicolumn{3}{|l|}{ Gender } \\
\hline Female & 67 & 62 \\
\hline Male & 31 & 29 \\
\hline Not specified & 2 & 2 \\
\hline \multicolumn{3}{|l|}{ Race } \\
\hline White & 80 & 74 \\
\hline Black & 6 & 6 \\
\hline Asian & 5 & 5 \\
\hline Multiracial & 3 & 3 \\
\hline Not specified & 3 & 3 \\
\hline \multicolumn{3}{|l|}{ Hispanic } \\
\hline Yes & 6 & 6 \\
\hline No & 91 & 85 \\
\hline Not specified & 2 & 2 \\
\hline \multicolumn{3}{|l|}{ Degree } \\
\hline Ph.D. & 86 & 80 \\
\hline Psy.D. & 10 & 9 \\
\hline Ed.D. & 2 & 2 \\
\hline Not specified & 2 & 2 \\
\hline \multicolumn{3}{|c|}{ Years since doctoral degree } \\
\hline $0-5$ & 22 & 20 \\
\hline $6-10$ & 18 & 17 \\
\hline $11-15$ & 13 & 12 \\
\hline $16-20$ & 13 & 12 \\
\hline $21-25$ & 9 & 8 \\
\hline $26+$ & 23 & 21 \\
\hline Not specified & 3 & 3 \\
\hline \multicolumn{3}{|l|}{ Academic rank } \\
\hline Instructor & 3 & 3 \\
\hline Assistant professor & 39 & 36 \\
\hline Associate professor & 23 & 21 \\
\hline Full professor & 17 & 16 \\
\hline Emeritus & 3 & 3 \\
\hline Other & 6 & 6 \\
\hline Not specified & 9 & 8 \\
\hline
\end{tabular}

of clinical hours were associated with higher numbers of non-billable clinical hours (see Table 2).

Respondents' self-perceived saturation of work capacity was correlated with degree of burnout, with hours worked in the AHC or clinical setting, and with hours worked at home, but not with other factors, such as hours of non-billable clinical work (see Table 2). Increased burnout was associated with dissatisfaction with one's professional position, productivity requirements in terms of expected hours of outpatient clinical service, and less enthusiastic recommendation that others pursue careers as psychologists in similar positions (see Table 2). 
Table 2 Factors perceived to increase the stress of AHC psychologists

\begin{tabular}{|c|c|}
\hline Factors & $\begin{array}{l}\text { Respondents } \\
\text { endorsing } \\
\text { item } \\
N \%\end{array}$ \\
\hline Clinical load/number of patients I am expected to see & $64(68.8)$ \\
\hline Salary & $51(54.8)$ \\
\hline Insufficient protected time for research & $50(53.8)$ \\
\hline Insufficient protected time for teaching/education/supervision & $50(53.8)$ \\
\hline Insufficient psychologists to meet the need & $48(51.6)$ \\
\hline Non-billable clinical activities (e.g., phone calls, documentation, etc.) & $48(51.6)$ \\
\hline Insufficient administrative staff & $41(44.1)$ \\
\hline Research productivity expectations & $38(40.9)$ \\
\hline $\begin{array}{l}\text { Clinical duties precluding other meaningful endeavors (e.g., educational/research activities } \\
\text { which are required for promotion) }\end{array}$ & $38(40.9)$ \\
\hline Low value placed on teaching/education/supervision & $37(39.8)$ \\
\hline EHR inefficiencies/burdens & $37(39.8)$ \\
\hline Institutional decisions made without communication/input from faculty & $37(39.8)$ \\
\hline Scarcity of research funding & $36(38.7)$ \\
\hline Budget cuts & $34(36.6)$ \\
\hline $\begin{array}{l}\text { Work load inhibits attendance at professional education activities (e.g., Grand Rounds, } \\
\text { faculty development, conferences, etc.) }\end{array}$ & $29(31.2)$ \\
\hline Insufficient clinical support staff & $26(28.0)$ \\
\hline Promotion and tenure process & $25(26.9)$ \\
\hline Insufficient research support staff & $24(25.8)$ \\
\hline Insufficient space for clinical activities & $24(25.8)$ \\
\hline Required administrative/institutional paperwork & $23(24.7)$ \\
\hline Promotion rates different than physicians & $22(23.7)$ \\
\hline Patient scheduling (appointment center) & $22(23.7)$ \\
\hline Poor communication between institutional leadership and faculty & $20(21.5)$ \\
\hline Insufficient technical support/clinical load reduction during EHR changes & $14(15.1)$ \\
\hline Insufficient education support staff & $13(14.0)$ \\
\hline Required training modules & $13(14.0)$ \\
\hline Relationship between psychologists and physicians & $12(12.9)$ \\
\hline Insufficient space for research activities & $12(12.9)$ \\
\hline Benefits & $9(9.7)$ \\
\hline Insufficient space for educational activities & $8(8.6)$ \\
\hline Inappropriate physician behavior & $6(6.5)$ \\
\hline Malpractice issues & $1(1.1)$ \\
\hline
\end{tabular}

Percentages derived with denominator of 93
Betweengroup analyses of variance evaluated wellness outcomes relative to demographics, workplace environment, and sources of stress. No significant differences emerged in any of the four wellness outcomes for gender, race, degree type, or US region of employment. Differences in perceived work capacity (i.e., $1=$ overextended; $2=$ at full capacity; $3=$ near full capacity; $4=$ have time for more) were seen across academic ranks $(F[2,70]=4.60, p=.01)$. Planned contrasts revealed associate professors described themselves as more taxed $(M=1.43, \mathrm{SD}=.51,21)$ than assistant professors $(M=2.03, \mathrm{SD}=.88, N=36)$ and full professors $(M=2.13, \mathrm{SD}=.96, N=16 ; t(70)=3.02, p=.004)$.
For descriptive purposes, respondents were queried about multiple potential stressors encountered by AHC psychologists with the item, "What factors do you believe increase the stress of psychology faculty (check all that apply)?" A summary of responses is presented in Table 3. Multiple sources of stress were endorsed with the top four being: clinical load (68.8\%), salary (54.8\%), insufficient protected time for research (53.8\%) and insufficient protected time for teaching/education/supervision $(53.8 \%)$. Few respondents $(<10 \%)$ endorsed stress related to benefits (or lack thereof), insufficient space, inappropriate physician behavior, or malpractice issues. 


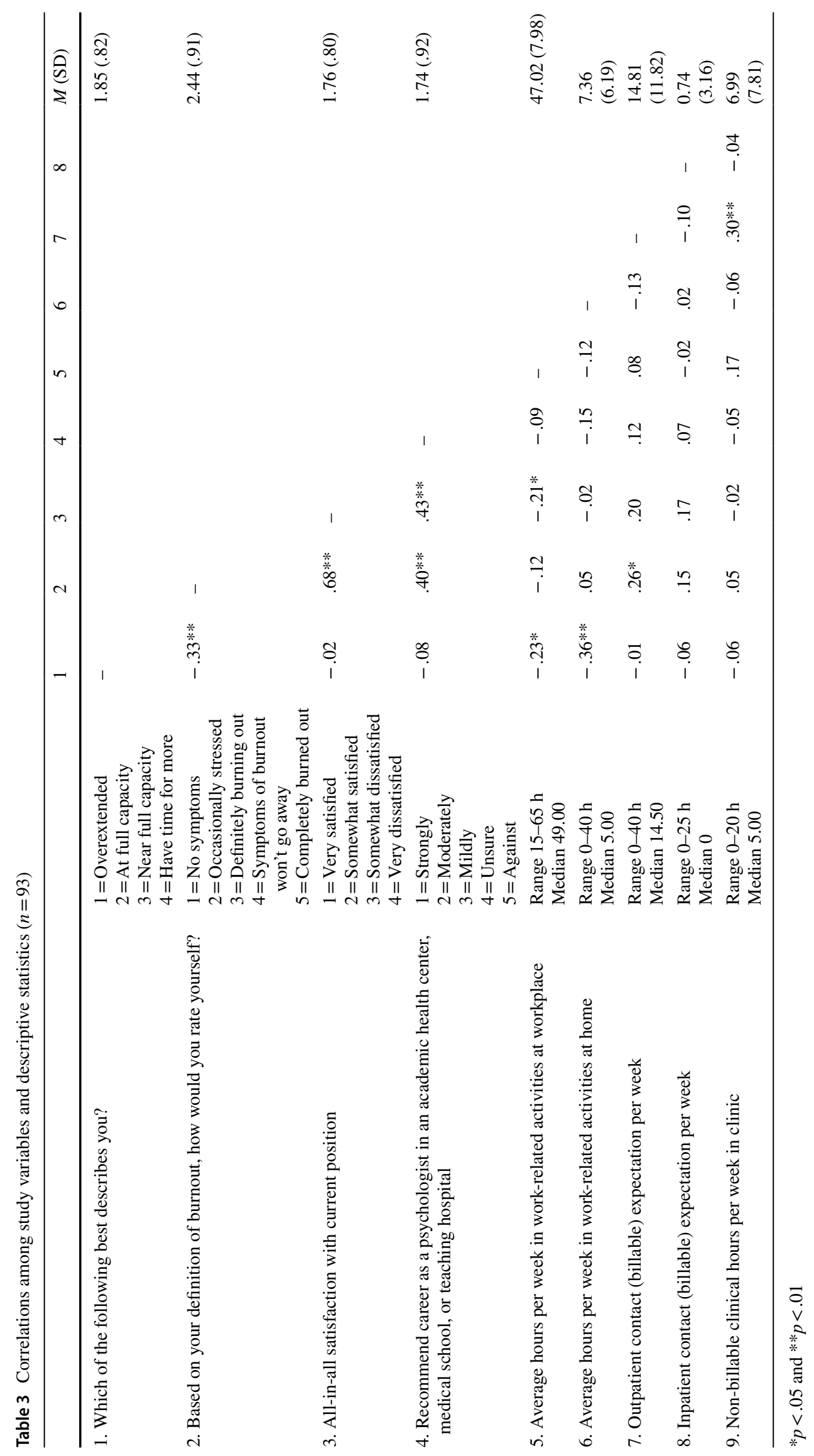




\section{Discussion}

Acknowledging the need for a more robust knowledge base regarding burnout in mental health professionals, this investigation characterizing the stressors and professional wellness of AHC psychologists represents a step in building such understanding. The results of the current study reveal the heterogeneity and breadth of stressors affecting psychologists in AHCs and raise concern that burnout may affect a sizeable proportion of AHC psychologists.

Albeit only a relatively low proportion of AHC psychologists described themselves as "definitely burned out" (i.e., 3\%), a third described definitive or persistent burnout symptoms, which is comparable to estimates of burnout in physicians (Shanafelt et al., 2015). If these rates are generalizable and extrapolated to the thousands of psychologists working in AHCs, or more broadly to populations of health service psychologists working in institutions with exposure to similar stressors, the number of psychologists experiencing significant burnout is far from trivial.

Psychologists' degree of perceived over-extension was associated with burnout and that higher burnout was strongly related to reduced job satisfaction. Such burnout affects not only the distressed individuals themselves, but can impact institutions, colleagues, trainees, and patients. Burnout may lead to diminished retention rates and increased recruitment challenges and costs. Distressed professionals may add further to the burdens of colleagues called upon to compensate for the performance or attendance challenges of psychologists experiencing varying degrees of burnout, as well as to provide emotional or other supports to them.

Respondents' most commonly endorsed sources of stress (i.e., $>50 \%$ of respondents) included clinical load, salary, insufficient protected time for research and educational pursuits, insufficient psychologists to meet clinical need, and frequent non-billable clinical activities. Many of these are similar to stresses reported in the physician literature (i.e., van Olmen et al., 2011; Ozyurt et al., 2006; Tomcavage \& Garrett, 2009; Robertson et al., 2017; Saver, 2009; Van Dyke \& Seger, 2013; Moses \& Dorsey, 2012), while others may be more unique to psychologists (e.g., insufficient salary). Interestingly, some sources of stress that were seen as not contributory by most respondents were negative physician behavior and malpractice concerns, which may reflect decreasing exposure to inappropriate workplace dynamics, growing attention to professionalism and interprofessionalism within institutions, or limited incidence of lawsuits. Alternatively, malpractice for AHC psychologists is typically covered by employers rather than individual professionals, perhaps reducing exposure to malpractice-related stress. Of course, just because a relatively low proportion of respondents might have rated a particular source of stress as low (e.g., space), it is important to recognize that for those psychologists who might be affected by that stressor, its impact can be substantial.

The survey revealed differences in burnout across academic ranks, with associate professors appearing to fare worse than assistant professors or full professors. The reasons for this finding are uncertain. One may speculate that associate professors are affected by maximal demands that normatively and simultaneously occur at this age and stage, both professionally (e.g., continued pursuit of promotion, adopting increasing administrative and leadership activities, etc.) and personally (e.g., being part of the "sandwich generation" balancing child-rearing responsibilities with caring for aging parents, new-onset personal health challenges, etc.). Regardless of the sources, these results suggest that despite having accrued more professional experiences, responsibilities, and recognition, mid-career psychologists may be at greater risk than is generally recognized for experiencing problematic levels of stress and associated burnout. This warrants consideration in developing prevention, detection, and intervention efforts despite mid-career psychologists' ostensible record of successes.

Limitations of this study warrant acknowledgement, including the modest size of the sample. This study was exploratory. Future larger-scale surveys of health service psychologists working in AHCs are recommended to determine how replicable these findings are and to gauge changes as well as to allow for analyses of covariates such as gender, race, ethnic group, etc. Because the survey was designed for the current study, its psychometrics have not been evaluated. However, items were created based on existing methods of measuring burnout and associated constructs. Additional research using longer, validated measures is needed.

Since this was the first investigation into these phenomena with this population, it is not known how fully the results are representative for all AHC psychologists, or for psychologists practicing in other settings. By virtue of being APAHC members, survey respondents may be a more professionally engaged and less professionally isolated sample, which could lead to under estimates of burnout rates. This professional engagement may provide normalization and validation of experience for psychologists in AHCs, in addition to peer consultation. For those engaged in professional organizations, such factors may be protective against burnout. Conclusions are also limited by the cross-sectional and self-report nature of the data and limited number of items. Despite these limitations, the study is a critical step toward filling the gap in the literature, offering information that raises concern about workforce wellness of psychologists in AHCs, and points to the importance for more focused research on identified areas of need. 
The paucity of research investigating wellness, stress, and burnout in psychologists in AHC settings is notable, with survey results supporting the topic as worthy of attention and additional methodologically sound inquiry. Research investigating sources of stress and opportunities and strategies for promoting individual-level wellness (e.g., resiliency skills) and institution-level efforts (e.g., wellness programs, procedural/policy changes, mentoring, robust faculty affairs programming promoting career development, increased infrastructure providing support for clinical, educational, and research activities, reassessments of productivity metrics for faculty success) are needed. Further efforts to identify predictors of burnout and factors associated with resiliency in the face of the stressors that AHC psychologists commonly face can inform prevention and intervention efforts. Future research should address factors that are as present for psychologists in medical culture as they are for other medical personnel (e.g., billing, reimbursement, nonbillable clinical activities), as well as those that are not often faced by our medical colleagues but faced by psychologists in AHCs (e.g., culture of respect/value as a doctoral-level provider, similar privileging and representation, CPT billing criteria and third party payer documentation demands for psychological services that increase work-related stress). Additionally, engaging psychology trainees and attendings in interprofessional education could enhance teamwork and increase the support that interdisciplinary team members can extend to each other while undertaking their collaborative activities. Lastly, more granular exploration of the stressors affecting psychologists may result in advocacy to change: (a) expectations, operations and processes within institutions, (b) public and private third party bureaucratic demands on psychologists' time and documentation burdens, and (c) EHR-related stressors as well as to lobby for additional administrative supports and resources that might mitigate some of the stressors.

Though our study did not generally identify demographic differences in wellness outcomes, further research examining sources of stress across gender, age, racial/ethnic group, geography, area of primary professional activity (teaching, clinical, research, administrative, leadership), clinical home, contact with other psychologists or mental health professionals, and acuity/complexity of clinical setting may assist with identifying at-risk groups and tailoring prevention strategies and interventions. The finding that academic rank appears to be associated with perceptions of work capacity, with associate professors endorsing being more taxed, suggests that interventions addressing burnout, wellness, and resilience may be enhanced by addressing unique stressors linked to specific developmental career stages. Exploring potential for different types of burnout and examining methods to not only prevent but promote recovery from burnout are also indicated.
In addition to further research, including psychologists in wellness interventions could enhance their well-being and effectiveness along with that of other AHC personnel. Systematic tracking and transparency of burnout rates, sources of stress, and suicide incidence is needed (Shanafelt \& Noseworthy, 2017). Facilitating culture change such as implementing strategies to change the "show no weakness" culture in academic healthcare and reduce stigmatization for seeking treatment (Castellucci, 2018), to the extent that these perceptions have counterparts in psychology, may also be cost-effective means of limiting the impact of psychologists' work-related stressors. With greater recognition of psychologist's stress in AHCs, it might be useful for psychologists to develop more opportunities for relating and collaborating that could provide support and a greater sense of shared purpose in fulfilling institutional missions. This could include social opportunities, such as periodic meetings of the psychology staff across academic departments so as to increase the cohesion of the psychological community within AHCs, help psychologists to get to better know each other outside of the what can often be siloed practice settings, and to encourage sharing of resources. It could also include educational meetings addressing diverse professional topics, serving as a virtual academic department even if psychologists may be distributed across departments and service lines, or the development of departments of medical or health psychology to provide a professional "home" for psychologists serving different medical areas (Rozensky, 2004).

A review and meta-analysis examining burnout interventions for physicians indicates that both individual approaches and broader organizational strategies can yield clinically meaningful reductions in burnout (West, Dyrbye, Erwin, \& Shanafelt, 2016). This literature has included calls for wellness programs and chief wellness officers at every institution (Kishore et al., 2018). Applying both individual and institutional strategies to psychologists and other AHC personnel at risk for or experiencing variable levels of burnout is a worthy undertaking. Opportunities to address this may offer leadership opportunities for which AHC psychologists may be particularly well suited, such as serving as chief wellness officers or assuming other professional wellness roles at the departmental, clinic, college, or institution level. In his keynote address at the 2019 APAHC Conference, Darrell Kirch (2019), President and CEO of the AAMC opined, "I think there might be at least 10 future chief wellness officers in this room."

Expertise in promoting professional wellness, individual-level resiliency skills, and development, implementation, and evaluation of program-level wellness interventions are squarely within the scope of psychologists' skill sets. Thus, APAHC, other professional associations, and institutional leaders are advised to explore ways to leverage psychologists' expertise and competence to provide service and 
leadership in addressing burnout, wellness, resilience, and their related clinical phenomena (e.g., anxiety, depression, suicide, disability) in their colleagues and throughout the healthcare workforce.

Funding This study was not funded.

\section{Compliance with Ethical Standards}

Conflict of interest Amy M. Williams, Bonney Reed, Mariella M. Self, William N. Robiner, and Wendy L. Ward declare that they have no conflict of interest.

Human and Animal Rights and Informed Consent All procedures performed in studies involving human participants were in accordance with the ethical standards of the University of Arkansas for Medical Sciences and with the 1964 Helsinki declaration and its later amendments or comparable ethical standards.

\section{References}

Advisory Committee on Colleague Assistance. (2006). American psychological association board of professional affairs advisory committee on colleague assistance. Washington, DC: American Psychological Association. Retrieved April 10, 2018 from www. apa.org/practice/resources/assistance/monograph.pdf

American Dental Association. (2017). 2015 Dentist well-being survey report. Janesville, WI. Retrieved from www.ebusiness.ada.org/ assets/docs/32944.PDF?OrderID=1364096

Arora, M., Asha, S., Chinnappa, J., \& Diwan, A. D. (2013). Review article: Burnout in emergency medicine physicians. Emergency Medicine Australia, 25, 491-495. https://doi.org/10.1111/17426723.12135.

Baker, K. (2003). Caring for ourselves: A therapist's guide to personal and professional well-being. Washington, DC: American Psychological Association.

Benson, M. A., Peterson, T., Salazar, L., Morris, W., Hall, R., Howletter, B., \& Phelps, P. (2016). Burnout in rural physician assistants: An initial study. Journal of Physician Assistant Education, 27, 81-83. https://doi.org/10.1097/JPA.00000000000000069.

Berjot, S., Altintas, E., Grebot, E., \& Lesage, F.-X. (2017). Burnout risk profiles among French psychologists. Burnout Research, 7 , 10-20. https://doi.org/10.1016/j.burn.2017.10.001.

Blue Ridge Academic Health Group (Winter, 2017-2018). The hidden epidemic: The moral imperative for academic health centers to address health professionals' well-being (Report No. 22). Retrieved December 20, 2018 from www.whsc.emory.edu/bluer idge/publications/archive/blue-ridge-winter2017-2018.pdf

Bodenheimer, T., \& Sinsky, C. (2014). From triple to quadruple aim: Care of the patient requires care of the provider. Annals of Family Medicine, 12, 573-576. https://doi.org/10.1370/afm.1713.

Branch, C., \& Klinkenberg, D. (2015). Compassion fatigue among pediatric health care providers. American Journal of Maternal Child Nursing, 40, 160-166. https://doi.org/10.1097/NMC.00000 00000000133.

Bridgeman, D., \& Galper, D. (2010, August). Listening to our colleagues-2009 APA practice survey results: Worries, wellness, and wisdom. Presented at the 118th Annual Convention of the American Psychological Association, San Diego, CA. Retrieved
November 9, 2018 from www.apa.org/practice/resources/assis tance/acca-2010-convention.pdf

Brigham, T., Barden, C., Dopp, A. L., Hengerer, A., Kaplan, J., Malone, B., Martin, C., McHugh, M., \& Nora, L. M. (2018). A journey to construct an all-encompassing conceptual model of factors affecting clinician well-being and resilience. NAM Perspectives. Washington, DC: National Academy of Medicine. https://doi.org/10.31478/201801b

Castellucci, M. (2018). Healthcare industry takes on high physician suicide rates, mental health stigma. Retrieved from www.moder nhealthcare.com/article/20180929/NEWS/180929901/medicalindustry-responds-to-physician-suicide-rates-mental-health

Center for Disease Control (CDC). (2019). National Institute for Occupational Safety and Health (NIOSH) General Social Survey Overview. Retrieved January 2, 2019 from www.cdc.gov/ niosh/topics/stress/qwlquest.html

Coster, J. S., \& Schwebel, M. (1997). Well-funcitoning in professional psychologist. Professional Psychology: Research and Practice, 28, 5-13.

Dandar, V. M., Bunton, S. A., \& Grigsby, R. K. (2018, July). Understanding burnout among faculty in medical schools. Poster presented at the AAMC Group on Faculty Affairs Meeting

Dolan, E. D., Mohr, D., Lempa, M., Joos, S., Fihn, S. D., Nelson, K. M., \& Helfrich, C. D. (2015). Using a single item to measure burnout in primary care staff: A psychometric evaluation. Journal of General Internal Medicine, 30, 582-587. https://doi. org/10.1007/s11606-014-3112-6.

Drummond, D. (2015). Physician burnout: It's origins, symptoms, and five main causes. Family Practice Management, 22(5), $42-47$.

Dyrbye, L. N., Shanafelt, T. D., Sinsky, C. A., Cipriano, P. F., Bhatt, J., Ommaya, A., ... Meyers. D. (2017). Burnout among health care professionals: A call to explore and address this underrecognized threat to safe, high-quality care. NAM Perspectives. Discussion Paper. National Academy of Medicine, Washington, DC. https:// doi.org/10.31478/201707b

Dyrbye, L. N., Varkey, P., Boone, S. L., Satele, D. V., Sloan, J. A., \& Shanafelt, T. D. (2013). Physician satisfaction and burnout at different career stages. Mayo Clinical Proceedings, 88, 1358-1367. https://doi.org/10.1016/j.mayocp.2013.07.016.

Dzau, V. J., Kirch, D. G., \& Nasca, T. J. (2018). To care is humanCollectively confronting the clinician-burnout crisis. New England Journal of Medicine, 378, 312-314. https://doi.org/10.1056/ NEJMp1715127.

Figley, C. R. (Ed.). (2002). Treating compassion fatigue. New York: Brunner-Routledge.

Firth-Cozens, J., \& Greenhalgh, J. (1997). Doctors' perceptions of the links between stress and lowered clinical care. Social Science and Medicine, 44, 1017-1022. https://doi.org/10.1016/S0277 -9536(96)00227-4.

Freudenberger, H. J. (1974). Staff burn-out. Journal of Social Issues, 30, 159-165. https://doi.org/10.1111/j.1540-4560.1974.tb007 06.x.

Freudenberger, H. (1990). Hazards of psychotherapeutic practice. Psychotherapy in Private Practice, 8(1), 31-34. https://doi. org/10.1300/J29v08n01_06.

Gardiner, M., Sexton, R., Durbridge, M., \& Garrard, K. (2005). The role of psychological well-being in retaining rural general practitioners. Australian Journal of Rural Health, 13, 149-155. https:// doi.org/10.1111/j.1440-1854.2005.00677.x.

Gold, K. J., Sen, A., \& Schwenck, T. L. (2013). Details on suicide among US physicians: Data from the national violent death reporting system. General Hospital Psychiatry, 35, 45-49. https://doi. org/10.1016/j.genhosppsych.2012.08.00.

Hoff, T., Carabetta, S., \& Collinson, G. E. (2017). Satisfaction, burnout, and turnover among nurse practitioners and physician assistants: 
A review of the empirical literature. Medical Care Research and Review., 76, 3-31. https://doi.org/10.1177/1077558717730157.

Institute for Healthcare Improvement (IHI) Institute of Medicine Committee. (2010). IHI triple aim initiative: Better care for individuals, better health for populations, and lower per capita costs. Retrieved August 13, 2017 from www.ihi.org/Engage/Initiatives/TripleAim/ Pages/default.aspx

Kirch, D. G. (2019, February). All hands on deck-Disruption in academic health centers. Presented at the 9th National Conference of the Association of Psychologists in Academic Health Centers, New Orleans, LA.

Kishore, S., Ripp, J., Shanafelt, T., Melnyk, B., Rogers, D., Brigham, T., ... Dzau, V. (2018). Making the case for the chief wellness officer in America's health systems: A call to action. Health Affairs Blog. https://doi.org/10.1377/hblog2018025.308059

Kleespies, P. M., Van Orden, K. A., Bongar, B., Bridgeman, D., Bufka, L. F., Galper, D. I., ... Yufit, R. I. (2011). Psychologist suicide: Incidence, impact, and suggestions for prevention, intervention, and postvention. Professional Psychology: Research and Practice, 42, 244-251. https://doi.org/10.1037/a0022805

Kullgren, K. A., Tsang, K. K., Ernst, M. M., Carter, B. D., Scott, E. L., \& Sullivan, S. K. (2015). Inpatient pediatric psychology consultation-liaison practice survey. Clinical Practice in Pediatric Psychology, 3, 340-351. https://doi.org/10.1037/cpp0000089.

Linzer, M. (2018). Clinician burnout and the quality of care. JAMA Internal Medicine, 178, 1331-1332. https://doi.org/10.1001/jamai nternmed.2018.3708.

Maslach, C., Jackson, S., \& Leiter, M. (1997). The Maslach Burnout inventory manual. In C. P. Zalaquett \& R. J. Wood (Eds.), Evaluating stress: A book of resources (pp. 191-281). New York: Scarecrow Press.

Maslach, C., \& Leiter, M. P. (2016). Understanding the burnout experience: Recent research and its implications for psychiatry. World Psychiatry, 15, 103-111. https://doi.org/10.1002/wps.20311.

Mendelsohn, D., Despot, I., Gooderham, P. A., Singhal, A., Redekop, G. J., \& Toyota, B. D. (2018). Impact of work hours and sleep on well-being and burnout for physicians-in-training: The resident activity tracker evaluation study. Medical Education. https://doi. org/10.1111/medu.13757.

Morse, G., Salyers, M. P., Rollins, A. L., Monroe-DeVita, M., \& Pfahler, C. (2012). Burnout in mental health services: A review of the problem and its remediation. Administration and Policy In Mental Health, 39, 341-352. https://doi.org/10.1007/s 1048 8-011-0352-1.

Moses, H., \& Dorsey, E. R. (2012). Biomedical research in an age of austerity. Journal of the American Medical Association, 308, 2341-2342. https://doi.org/10.1001/jama.2012.14846.

Mott, D. A., Doucette, W. R., Gaither, C. A., Pedersen, C. A., \& Schommer, J. C. (2004). Pharmacists' attitudes toward worklife: Results from a national survey of pharmacists. Journal of the American Pharmacists Association, 44, 326-336.

National Academy of Medicine. (2017). Action collaborative on clinician well-being and resilience. Retrieved February 12, 2019 from www.nam.edu/initiatives/clinician-resilience-and-well-being/

Ozyurt, A., Hayran, O., \& Sur, H. (2006). Predictors of burnout and job satisfaction among Turkish physicians. QJ Medicine, 99, 161-169. https://doi.org/10.1093/qjmed/hcl019.

Panagopoulou, E., Montgomery, A., \& Benos, A. (2006). Burnout in internal medicine physicians: Differences between residents and specialists. European Journal of Internal Medicine, 17, 195-200. https://doi.org/10.1016/j.ejim.2005.11.013.

Peterson, C., Stone, D. M., Marsh, S. M., Schumacher, P. K., Tiesman, H. M., McIntosh, W. L, ... Luo, F. (2018). Suicide rates by major occupational group-17 states, 2012 and 2015. Morbidity and Mortality Weekly Report, 67(45), 1253-1260. https://doi. org/10.15585/mmwr.mm6745a1.
Pololi, L., \& Knight, S. (2005). Mentoring faculty in academic medicine. A new paradigm? Journal of General Internal Medicine, 20, 66-70. https://doi.org/10.1111/1525-1497.2005.05007.x.

Pope, K. S., \& Tabachnick, B. G. (1994). Therapists as patients: A national survey of psychologists, experiences, problems, and beliefs. Professional psychology: Research and Practice, 25, 247-258. https://doi.org/10.1037/0735-7028.25.3.247.

Raquepaw, J. W., \& Miller, R. S. (1989). Psychotherapist burnout: A componential analysis. Professional Psychology: Research and Practice, 20, 32-36. https://doi.org/10.1037/0735-7028.20.1.32.

Robertson, S. L., Robinson, M. D., \& Reid, A. (2017). Electronic health record effects on work-life balance and burnout within the i3 population collaborative. Journal of Graduate Medical Education, 9, 479-484. https://doi.org/10.4300/JGMED16 00123.1.

Rozensky, R. H. (2004). Freestanding psychology: The only way in academic health centers. Journal of Clinical Psychology in Medical Settings, 11, 127-133. https://doi.org/10.1023/B:JOCS.00000 25724.09384.3d.

Rupert, P. A., Miller, A. O., \& Dorociak, K. E. (2015). Preventing burnout: What does the research tell us? Professional Psychology: Research and Practice, 46, 168-174. https://doi.org/10.1037/ a0039297.

Rupert, P. A., \& Morgan, D. J. (2005). Work setting and burnout among professional psychologists. Professional Psychology: Research and Practice., 36, 544-550. https://doi. org/10.1037/0735-7028.36.5.544.

Saver, C. (2009). OR leaders face tightened budgets, loss of benefits in wake of recession. OR Manager, 25, 1. Retrieved from http:// search.ebscohost.com.proxy.lib.wayne.edu/login.aspx?direc $\mathrm{t}=$ true $\& \mathrm{db}=\mathrm{cmedm} \& \mathrm{AN}=19886568 \&$ site $=$ ehost-live \&scope $=$ site.

Severn, M. S., Searchfield, G. D., \& Huggard, P. (2012). Occupational stress amongst audiologists: Compassion satisfaction, compassion fatigue, and burnout. International Journal of Audiology, 51, 3-9. https://doi.org/10.3109/14992027.2011.602366.

Shanafelt, T. D., Hasan, O., Dyrbye, L. N., Sinsky, C., Satele, D., Sloan, J., \& West, C. P. (2015). Changes in burnout and satisfaction with work-life balance in physicians and the general US working population between 2011 and 2014. Mayo Clinic Proceedings, 90, 1600-1613. https://doi.org/10.1016/j.mayocp.2015.08.023.

Shanafelt, T. D., \& Noseworthy, J. H. (2017). Executive leadership and physician well-being: Nine organizational strategies to promote engagement and reduce burnout. Mayo Clinic Proceedings, 92, 129-146. https://doi.org/10.1016/j.mayocp.2016.10.004.

Shelledy, D. C., Mikles, S. P., May, D. F., \& Youtsey, J. W. (1992). Analysis of job satisfaction, burnout, and intent of respiratory care practitioners to leave the field or the job. Respiratory Care, $37,46-60$.

Shi, Y., Gugio, P. D., Crowe, R. P., \& Way, D. P. (2018). A Rasch analysis validation of the Maslach Burnout inventory-Student survey with preclinical medical students. Teaching and Learning in Medicine, 21, 1-16. https://doi.org/10.1080/10401334.2018.1523010.

Studer Group. (February, 2012). Physician burnout: Preparing for a "perfect storm". Straight A Review, 1-7. Retrieved January 26, 2019 from https://www.studergroup.com/getmedia/fea54 126-168b-4ba3-9866-8f584e4e7fa8/physician_burnout_strai ght_a_review.pdf.aspx

The Physicians Foundation. (2014). 2014 survey of America's physicians: Practice patterns \& perspectives. Retrieved February 12, 2019 from www.physiciansfoundation.org/wp-content/uploa ds/2017/12/2014_Physicians_Foundation_Biennial_Physician_ Survey_Report.pdf

Tomcavage, J., \& Garrett, M. B. (2009). Care coordination: Case managers "connect the dots" in new delivery models. Commission for Case Manager Certification, 1, 1-8. 
Van Dyke, A., \& Seger, A. M. (2013). Finding, keeping, and revitalizing the meaning in family medicine. International Journal of Psychiatry in Medicine, 45, 323-331. https://doi.org/10.2190/ PM.45.4.c.

van Olmen, J., Ku, G. M., Bermejo, R., Kegels, G., Hermann, K., \& Van Damme, W. (2011). The growing caseload of chronic lifelong conditions calls for a move towards full self-management in low-income countries. Globalization and Health, 7, 38. https:// doi.org/10.1186/1744-8603-7-38.

Welp, A., \& Manser, T. (2016). Integrating teamwork, clnician occupational well-being and patient safety - development of a conceptual framework based on a systematic review. BMC Health Services Research, 16, 281-325. https://doi.org/10.1186/s1291 3-016-1535-y.

West, C. P., Dyrbye, L. N., Erwin, P. J., \& Shanafelt, T. D. (2016). Interventions to prevent and reduce physician burnout: A systematic review and meta-analysis. Lancet, 388, 2272-2281. https:// doi.org/10.1016/S0140-6736(16)31279-X.

Williams, E. S., \& Skinner, A. C. (2003). Outcomes of physician job satisfaction: A narrative review, implications, and directions for future research. Health Care Management Review, 28, 119-139. https://doi.org/10.1097/00004010-20030400-00004.

World Health Organization. (2019). Burn-out an "occupational phenomenon": International Classification of Diseases. Retrieved May 30, 2019 from www.who.int/mental_health/evidence/ burn-out/en/

Wright, J. G., Khetani, N., \& Stephens, D. (2011). Burnout among faculty physicians in an academic health science centre. Paediatrics \& Child Health, 16, 409-413. https://doi.org/10.1093/ pch/16.7.409.

Zwack, J., \& Schweitzer, J. (2013). If every fifth physician is affected by burnout, what about the other four? Resilience strategies of experienced physicians. Academic Medicine, 88, 1-8. https://doi. org/10.1097/ACM.0b013e318281696b.

Publisher's Note Springer Nature remains neutral with regard to jurisdictional claims in published maps and institutional affiliations. 